Environmental Economics and Policy Studies

April 2017, Volume 19, Issue 2, Pages 233-247

Achimer

http://dx.doi.org/10.1007/s10018-016-0153-6

http://archimer.ifremer.fr/doc/00334/44486/

(C) Society for Environmental Economics and Policy Studies and Springer

Japan 2016

\title{
On the influence of environmental factors on harvest: the French Guiana shrimp fishery paradox
}

\author{
Sanz Nicolas ${ }^{1}{ }_{-}^{*}$, Diop Bassirou ${ }^{1}$, Blanchard Fabian ${ }^{2,3}$, Lampert Luis ${ }^{4}$
}

${ }^{1}$ CEREGMIA, Université des Antilles et de la Guyane, Campus de Troubiran, Pôle, d'Enseignement Supérieur, Bât. E-Bur. 205, 2091 route de Baduel, BP 792, 97337 Cayenne Cedex, France

${ }^{2}$ UMSR 3456, Laboratoire Ecologie, Evolution, Interactions des Aystèmes Amazoniens (LEEISA),

Université de Guyane, CNRS, IFREMER, 97300 Cayenne, France

${ }^{3}$ Ifremer, BP 477, 97331 Cayenne, French Guiana, France

${ }^{4}$ Ifremer, Centre Bretagne, ZI de la Pointe du Diable, CS 10070, 29280 Plouzané, France

\begin{abstract}
:
The purpose of this paper is to investigate the environmental nature of the French Guiana shrimp fishery dynamics through an empirical analysis. To do so, we specify a global harvest production function, in which the output depends on the number of days at sea and the stock level. In addition, we use some environmental variables representing the 'El Niño' and 'la Niña' phenomena, the sea surface temperature, and the flow of some Amazonian rivers as instruments. This method enables us to correct the well-known simultaneous bias between the harvest and the stock levels and to show that harvest is significantly dependent on the environmental factors analyzed, which may compromise the future of the French Guiana shrimp fishery in the context of climate change.
\end{abstract}

Keywords : Fisheries, Harvest production function, El Niño, La Niña, Amazonian rivers 


\section{Introduction}

Since the mid 90's, environmental issues have become central in the public debate (Dunlap et al., 1991). Nowadays, next to the $\mathrm{CO}_{2}$ 's emissions limitation and the management of water and wastes, the question of the safety of biodiversity also represents a crucial issue. Among all the numerous species the French Guiana entails, the shrimp constitutes a good example of a species being exploited for economic purposes that has almost totally collapsed in recent years (Lampert, 2011a) ${ }^{1}$.

The French Guiana coast's proximity of the Amazon estuary results in the presence of a muddy corridor bounded by a red line (see Figure 1). Two shrimp species are mainly exploited in the shrimp fisheries, the brown and the pink shrimps (resp. Farfantepenaeus subtilis and Farfantepenaeus brasiliensis). The Farfantepenaeus subtilis represents more than $85 \%$ of shrimp landings. The other species, fished farther offshore and eastern limit of their spatial distribution, represents the remainder. Currently the number of employees is about 135, and essentially foreign nationality (Guyana, Suriname, Brazil). The industry achieves a turnover amounted to $€ 6.52$ millions and the weighted average price collected by the shrimp industry per $\mathrm{kg}$ thus came to $€ 6.91$. The French Guiana shrimp fishery started in the late 60 's with the US fleet activity. All the boats are Florida-style shrimp trawlers, each using two trawls at the same time. Japanese boats also exploited shrimps, but the whole fleet became progressively French between 1970 and 1990. Over this period, the US-Japanese fleet increased up to 80 trawlers. Since 1992, the whole fleet is only composed with french trawlers targeting shrimps on the continental shell. The stock assessment has been firstly performed each two years by a working group within the institutional and international framework of the Western Central Atlantic Fishery Commission (WECAFC) up to 1999, and has then been undertaken by the Ifremer (French institute of research for the exploitation of the sea) for management advice since the eighties, allowing for a strong knowledge of the population. The method used for assessment is the well-known "Virtual Population Analysis" (VPA), carried out on a monthly step basis which allows to obtain the recruit abundance as well as the spawning stock biomass and the fishing mortality.

One particular interest it presents is that its stock has steadily decreased over years though the effort and harvest levels have followed quite the same trend. Yet, some management rules and instruments have been progressively implemented or reinforced after the creation of the Exclusive Economic Zone.

\footnotetext{
${ }^{1}$ The French Guiana constitutes one of the richest areas in terms of biodiversity in the world, the fourth as marine fish is concerned.
} 


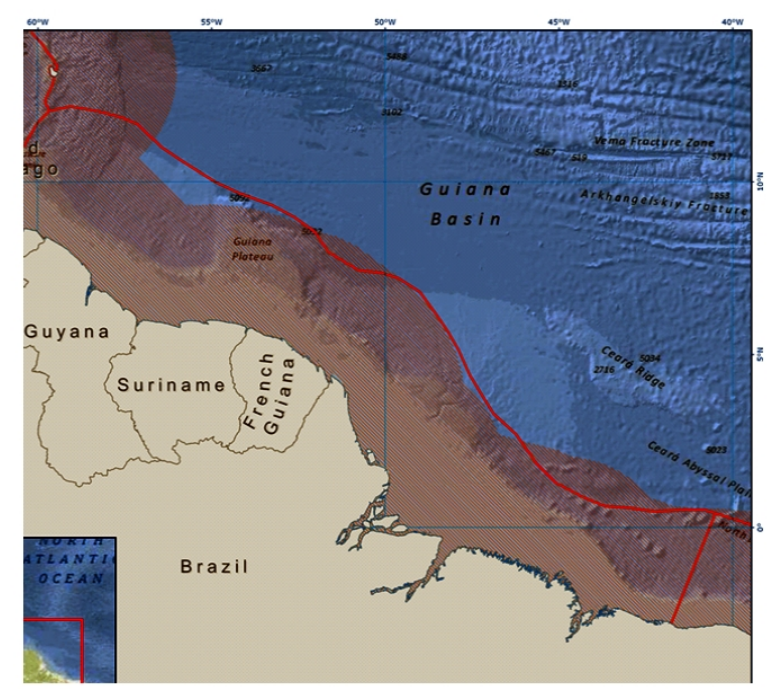

Figure 1: The Gianas-Brazil shrimping grounds

The management of the fishery is in compliance with European legislation. A total allowable catch (TAC) of 4108 tons/year (about 340 tons/month) (for brown and pink shrimps has been adopted in 1983, of which $108 \mathrm{t} /$ year. can be caught by neighbouring countries (Surinam, Trinidad, Barbade). Compared to the historical catch, the TAC level has never been fully achieved. This TAC level has not been changed until 2011, despite the decreasing trends in biomass and landings. In 1991, a license system has been introduced for both species. The main objective was initially to limit the number of boats in order to protect the shrimp resource. Licenses are provided without fees. The main objective was initially to limit the number of boats to protect the shrimp resource. However, the license system did not seem to be in fact an active or efficient resource management tool. Indeed, the year abundance of shrimp is mainly correlated with recruitment but not with effort like e.g. the number of boats or the number of days at sea. The number of licenses was slightly reduced from 69 in 1991 to 63 in 1999, and to 49 in 2010. During this period, the number of active shrimp trawlers was less than the number of licenses (less than half in 2006). The license system could have been a tool to adjust the number of boats in order to improve economic results, but this objective was not explicitly addressed by the management system. Finally, there exist also some spatial restrictions: in order to limit the impact of trawling on juvenile shrimps and avoid conflicts with the inshore small-scale fishery, trawling is forbidden in inshore waters less than 30 meters depth. 
This rule is more restrictive than the spatial limitation applied to trawlers in European waters. All in all, the economic dynamics of the fishery has been characterized by a diminution of the fleet size, to concentrate the fishing activities on a reduced number of profitable vessels. In addition it will be noted that the profitability has declined in this sector due to aquaculture growing globally. This results in lower prices for shrimp.

Nevertheless, despite this low effort level, the whole shrimp stock has strongly decreased between 1990 and 2009, which seems to constitute a paradox. Newfoundland are closed and most other major stocks have been heavily over-exploited despite extensive and intensive management efforts (Healey and Hennessey, 1998). Regulation may be imcompatible or inadequate with the goal of making some fishery sustainable. This suggests that other factors, like environmental shocks, could explain the above statement. The French Guiana sea fishing area may be indeed affected by e.g. the large guianan rivers and some climatic phenomena like 'El Niño' and 'La Niña'. The temperature, which can be considered as a general proxy of global climatic changes, may also play an important role here. Hence, a more efficient management of this fishery would consist in a bio-economic approach accounting for the environmental trends and the economic context, in accordance with the new framework of the ecosystem based fisheries management.

Knowledge of present biogeographical limits is thought to make possible to indentify sensitive species (Hart and Reynolds, 2002). Climate mapping is currently used to predict the future distributions of species. Actually bioclimatic models are used to assess potential changes in species distributions and to identify those species that may be most vulnerable to climate change. Ishimura et al. (2013) study a three agent game theoretic-bioeconomic model of the Pacific Sardine stock's abundance and biomass distribution that accounts for decadal-scale climate change. These models attempt to match the current distribution of a species with a number of climatic variables, producing an envelope that describes the climate within a species current range. Then potential changes in distribution under various climate scenarios are estimated with the parameters of the envelope (Mooney, 1991; Rogers and Randolph 1993; Huntley, 1994; Mack, 1996; Beaumont and Hughes, 2002).

This method is based on the assumption that range and abundance are determined first and foremost by the physiological tolerances of individual organisms. Physiological tolerance can be defined as following. Species are adapted to a given range of environmental conditions defining its envelope, with an optimal environmental window, around the mean value of the range. Hence species abundance may follow some gaussian distribution within its envelope such as abundance declines towards the edges of the species range (Hengeveld and Haeck, 1982; Brown et al., 1996; Maurer, 1999). Moreover 
because physiological tolerances limits are reached on these edges, species abundance may show there more rapid responses to small shifts in climate than near the midpoint of the range (Gaston, 1990; Lawton, 2000). In local communities, the mean abundance and temporal variability may then depend on the range position.

The purpose of this paper is thus in a first step to investigate the effects of some environmental phenomena on the working of the French Guiana shrimp fishery under a statistical view point. In order to do so, we propose an empirical analysis of a harvest production function where output depends on an effort variable (the number of days at sea) and the stock level. Besides, we introduce additional pure environmental variables to correct a specific simultaneous bias problem, which in turn enables to highlight the role that these variables play in improving the explanatory power of the model. We have chosen some variables about which data were available: the Niño and Niña phenomena, the sea surface temperature, and the flow of the Amazon, the Aprouague, the Comte, the Maroni, and the Oyapock rivers. Output elasticities with respect to usual and environmental inputs are then analyzed in detail.

The paper is organized as follows. The second section introduces methods with variables' description and production functional form. The third section summarizes the main results and discussion. And the last section entails some concluding remarks.

\section{Methods}

\subsection{Variables and data set}

Shrimp Landings and VPA calculations (Figure 2, first plate): The whole shrimp production of French Guiana is landed at the Larivot port. We use the data obtained from the sampling carried out since 1989 by Ifremer. We determine the species (some pink royal shrimps - Farfantepenaeus Brasiliensis - are mixed with the brown shrimps F. subtilis) and sex each subject. Size distributions for males and females are different. The abundance values of the recruits and stock were monthly performed by age-based Virtual Population Analysis (VPA) in accord with Sparre and Venema (1998). The male and female were evaluated separately. The monthly length distributions (19892009) were split into 7 nominal age-groups (2 to 8 plus-group) for both males and females. A specific $\mathrm{R}$ package script was developed for this calculation because more than 200 cohorts have to be calculated simultaneously (Lampert, 2011a, 2011b). The VPA Ifremer calculations were performed with the 


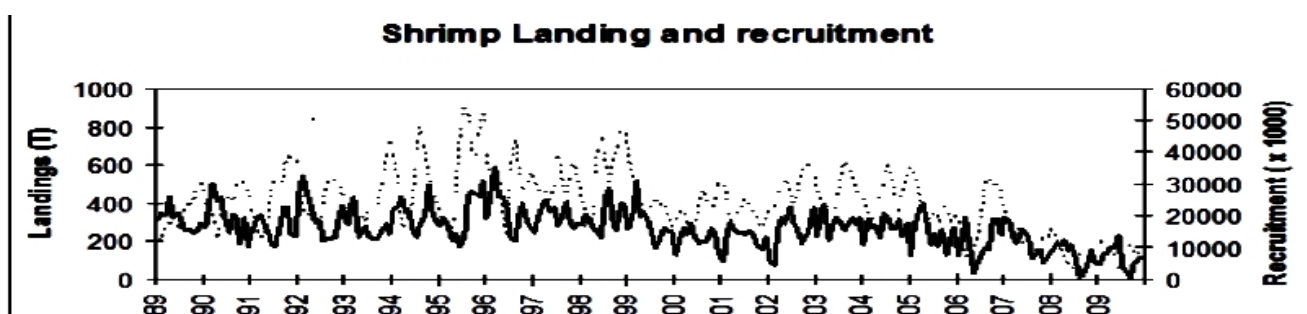

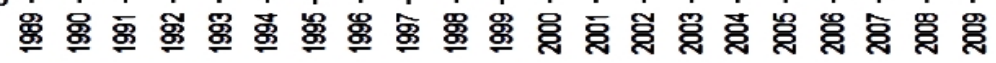

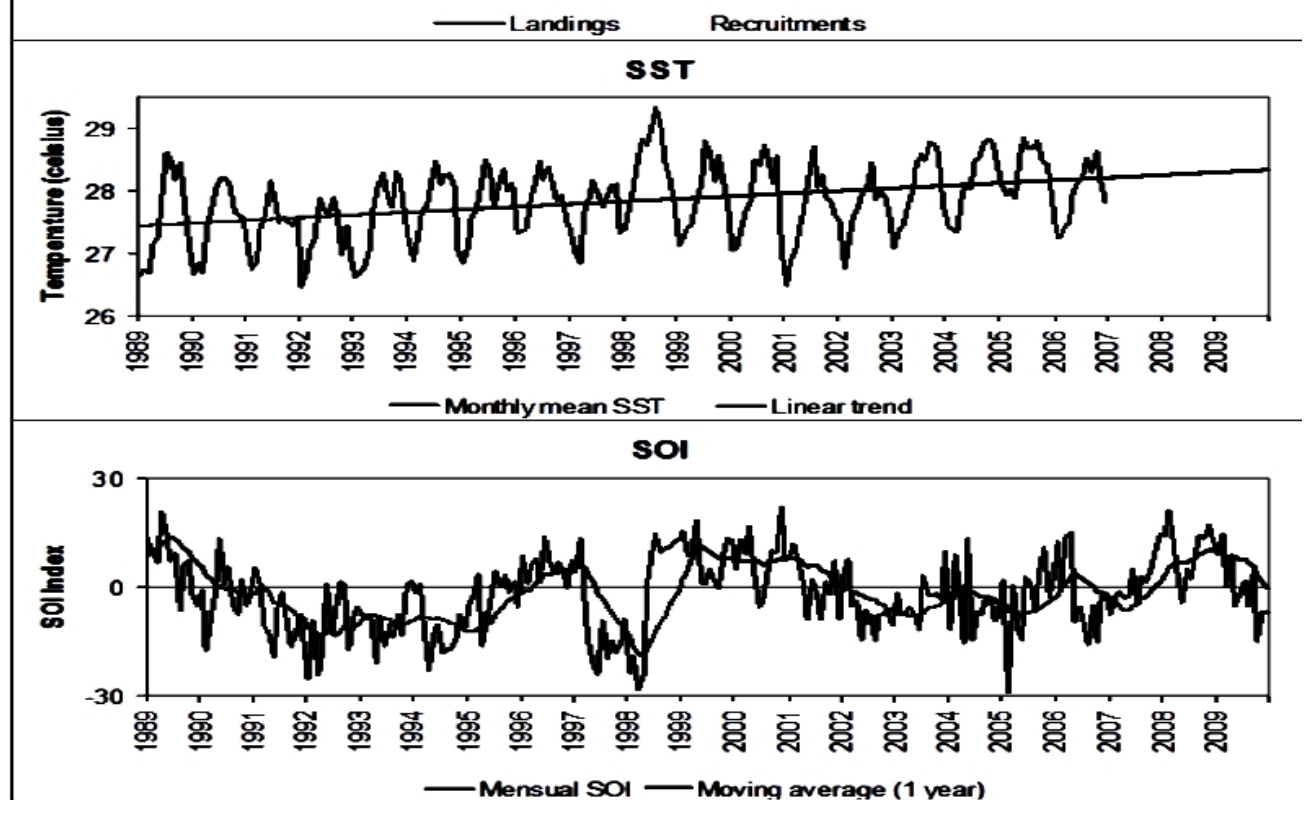

Figure 2: Monthly variations of the shrimp landing and recruitment, Sea Surface Temperature (SST) and SOI index

local shrimps growth rates (Vendeville et al., 2008).

Sea surface temperatures (SST) (Figure 2, second plate): The monthly sea surface temperatures $(S S T)$ were provided by the National Climatic Data Center (NCDC) database. This monthly one-degree global SST climatology was constructed using the analyses carried out by the Climate Prediction Center (CPC/NOAA). The one degree climatology and analyses derived from monthly Optimum Interpolation (OIv2). The area coverage of the data is $2^{\circ}-9^{\circ} \mathrm{N}$ and $47^{\circ}-59^{\circ} \mathrm{W}$. The analysis used buoy and ship data sets, satellite SST data, and SST's simulated by sea-ice coverage. The OI.v2 analysis is described in Reynolds et al. (2002).

El Niño-La Niña index (Figure 2, third plate): The Southern Oscillation Index, or SOI, gives an indication of the development and intensity of El 
Niño or La Niña events in the Pacific Ocean. The SOI is calculated using the pressure differences between Tahiti and Darwin. There are several methods to calculate the SOI. The method used by the Australian Bureau of Meteorology is the Troup SOI which is the standardised anomaly of the Mean Sea Level Pressure difference between Tahiti and Darwin. It is calculated as follows:

- $S O I=10^{*}($ Pdiff-Pdiffav $) / S D(P$ diff $)$

where Pdiff $=$ (average Tahiti MSLP for the month) - (average Darwin MSLP for the month),

- Pdiffav = long term average of Pdiff for the month in question

- $S D($ Pdiff $)=$ long term standard deviation of Pdiff for the month in question.

Rivers flow ( $\mathrm{m}^{3} /$ seconde) (Figure 3): The mensual means of the Amazon, Maroni and Oyapock rivers flows were loaded on the ORE HYBAM website. The Environmental Research Observatory (ORE) HYBAM (Geodynamical, hydrological and biogeochemical control of erosion/alteration and material transport in the Amazon basin) operates since 2003. In 2011, the OREHYBAM is a component of the GET (Geosciences Environnement Toulouse) (UMR 5563 CNRS / IRD UR 234 / UPS / CNES), Observatoire MidiPyrénées (OMP). The other local flow rivers were obtained by the guianian "direction de l'environnement, de l'aménagement et du logement" (DEAL). Figure 3 describes the same flow's trend $\left(\mathrm{m}^{3} / \mathrm{s}\right)$ between Amazon and the main guianan rivers.

\subsection{Cobb-Douglas (C-D) production function}

In fisheries economics, the most treated function is the Schaefer (1957) one, which is linear in both effort and stock size and homogeneous of degree two. According to these assumptions, catch per unit effort $(\mathrm{H} / \mathrm{E})$ is proportional to stock size at all levels of effort and stock, and the distribution of fish is uniform (see Bjørndal, 1987). Whereas the use of such a function can be justified in a first step, its use is unrealistic for fisheries of schooling species (Clark, 1976, p. 235). Hence, we rather retain a more general Cobb-Douglas functional form. This function still implies that catch-input elasticities remain constant, i.e. independent of the scale of fishing operations or the fish stock's level. Besides, this kind of single species harvest functions enables to avoid the risks of misspecification, which could result from multi-species modelling (Peña et al, 2007). At last, inter-species biological interactions are 


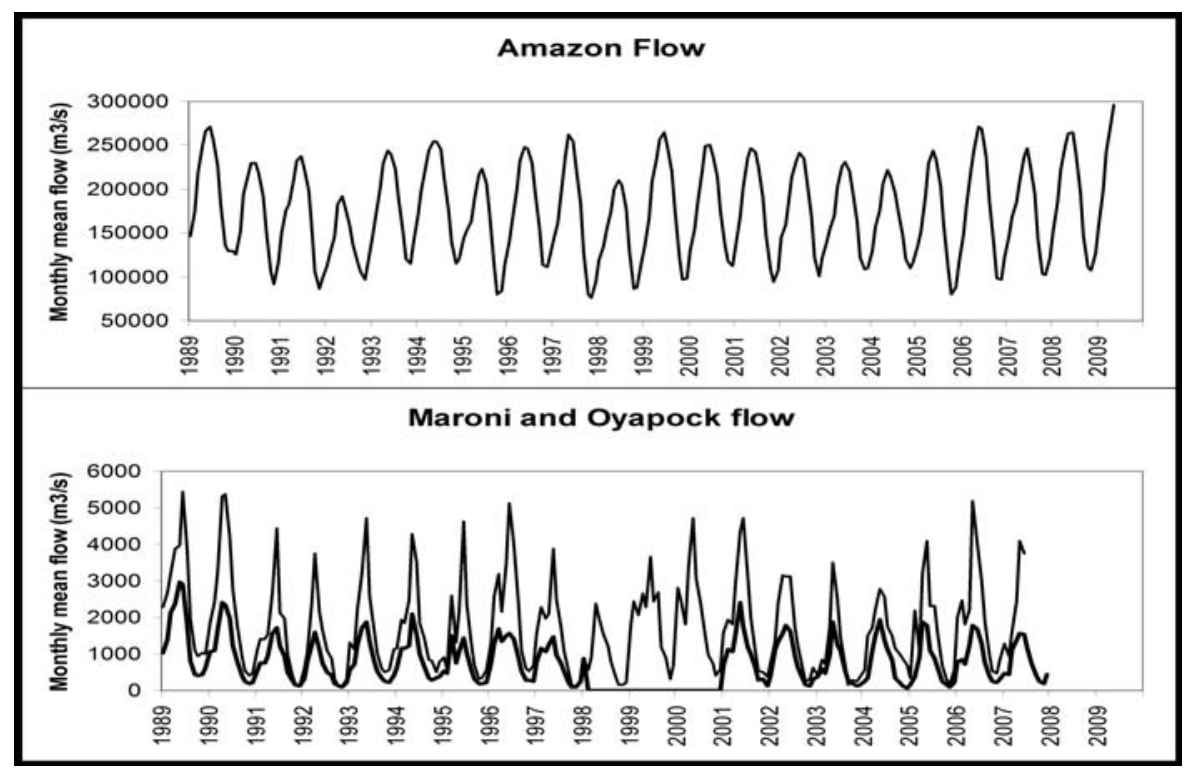

Figure 3: Mean monthly flow of the Amazon and main guianian rivers

still not well identified in the fishing zone considered here. Moreover, the Cobb-Douglas function is very well-established in the litterature on fishery economics (Bjørndal, 1987; Bjørndal, 1989; Bjørndal et al., 1993), although other production functions integrating e.g. boats' capacity could also be considered (see Yagi and Managi, 2011). According to the Cobb-Douglas form retained here, the harvest is related to economic, biological, and environmental exogenous variables as follows:

$$
H_{t}=q E_{t}^{\alpha} S_{t}^{\beta}
$$

where $q, E_{t}$, and $S_{t}$ respectively denote the catchability coefficient, the fishing effort level expressed as the number of days at sea, and the stock size. The parameters $\alpha$ and $\beta$ respectively represent the elasticities of the harvest level with respect to effort and stock.

Times series data for the Guianan shrimp fisheries were obtained from the Ifremer. They are monthly) available from January 1990 to December 2009 involving $N=240$ observations. The data set includes details for whole fleet about harvest (the landed tonnage), inputs like the stock and the total number of days at sea (monthly operating days off shore), and the environmental factors as the rivers' flow, the sea surface temperature and the Niño and Niña indicators.

The Stock: the abundance values of the recruits and stock were monthly performed by age-based Virtual Population Analysis (VPA); see Section 2. 
The Harvest variable to be explained corresponds to monthly landings of shrimp in tons for the whole fleet.

The Effort variable used for capturing the effects of fishing effort is a monthly number of total days during which the fleet is offshore. It includes the travelling time to the area where the fishing activities take place.

Niño and Niña variables describe the corresponding phenomena and are captured through the SOI ("Southern Oscillation Index") measure and used in the regression as dummies. This oscillation has its largest signature in and over the tropical Pacific and Indian oceans but it also affects oceanic and atmospheric conditions globally. The Niño yields a disruption of temperature in the tropical Pacific Ocean that has important weather and climate consequences around the globe ${ }^{2}$. The Niño currents usually last for several months, resulting in the reduction of nutrients and a corresponding dissipation of fish stocks (Sun et al., 2006). The Niña is opposite for this other phase of the SOI when sea surface temperatures in the central and eastern tropical Pacific are unusually low and when the trade winds are very intense. We suppose here that an oceanic episode of the Niño occurs when the SOI is lower than -8 and that an episode of the Niña occurs when the SOI is greater than 8 . Besides, in order to take the persistence and the intensity of such phenomena into account, we have lagged the latter dummies of one year (12 months), which corresponds to the Nino(-12) and Nina(-12) additional variables.

The (sea surface) Temperature variable is measured in degrees celsius and is equal to the monthly mean during the estimated period. It is used in the regression as an instrumental variable.

Finally, in all regressions, we use the effort level as the exogenous variable and as intrumental variables that are correlated with the endogenous one (Stock). The instruments used are: the variables juveniles and adults, some pure environmental variables representing the Niño and the Niña phenomena, the SST, and those that denote the flow of the large rivers that are located in French Guiana. Among them, data are only available for the Aprouague, the Comte, the Maroni, and the Oyapock. Next to the local rivers that are of interest since they are located close to the fishing zone, we also integrate to the analysis a very singular river due to its size, the Amazon. The flow of the above rivers has been evaluated in $\mathrm{m}^{3} / \mathrm{sec}$.

The following logarithm of the Cobb-Douglas harvest function (1) will be estimated:

\footnotetext{
${ }^{2}$ The term "El Niño" (meaning the "Christ Child" in Spanish) is used by fishermen in Ecuador and Peru to refer to a warmer than normal ocean current observed immediately after Christmas every few years.
} 
$(2)$

$$
\ln H_{t}=\ln q+\alpha \ln E_{t}+\beta \ln S_{t}+\varepsilon_{t}
$$

where $\varepsilon_{t}$ denotes error terms.

\section{Results and discussion}

We first use ordinary least squares (OLS) to estimate the harvest production function. Results are presented in Table 2 (Model 1). Table 1 and Table 1a. show descriptive statistics for production inputs, output and instrumental variables.

Table 1: Descriptive statistics for Stock, Effort, Harvest, Temperature

\begin{tabular}{ccccc}
\hline \hline & Stock (tons) & Effort (days at sea) & Harvest (tons) & Temperature $\left({ }^{\circ} \mathrm{C}\right)$ \\
\hline Mean & 730.88 & 1088.67 & 265.88 & 27.85 \\
Median & 734.21 & 1209 & 262.5 & 27.89 \\
Maximum & 1463.54 & 1842 & 586 & 29.33 \\
Minimum & 118.5 & 22 & 10 & 26.47 \\
Std. D & 253.51 & 381.82 & 104.85 & 0.57 \\
\hline
\end{tabular}

Table 1a: Descriptive statistics for Amazon, Maroni, Oyapock, Aprouague, and Comte rivers' flow

\begin{tabular}{cccccc}
\hline \hline & Amazon $\left(\mathrm{m}^{3} / \mathrm{s}\right)$ & Maroni $\left(\mathrm{m}^{3} / \mathrm{s}\right)$ & Oyapock $\left(\mathrm{m}^{3} / \mathrm{s}\right)$ & Aprouague $\left(\mathrm{m}^{3} / \mathrm{s}\right)$ & Comte $_{\left(\mathrm{m}^{3} / \mathrm{s}\right)}$ \\
\hline Mean & 173721 & 1760 & 861 & 303.4 & 103.9 \\
Median & 174600 & 1524 & 755 & 290.54 & 88.30 \\
Maximum & 296000 & 5438 & 2969 & 675.53 & 417.13 \\
Minimum & 76390 & 100 & 76.81 & 74.19 & 9.35 \\
Std. D & 52814 & 1277 & 616.56 & 149.50 & 74.50 \\
\hline \multicolumn{7}{r}{ Std. D : Standard deviation }
\end{tabular}


Table 2: Result from OLS estimation Eq.2 and TSLS estimation of the shrimp harvest function with Niño,

Niña, the sea temperature and the rivers' flow as instrumental variables

\begin{tabular}{|c|c|c|c|c|c|c|c|}
\hline Models & Instruments/Variable & Constant & Effort & Stock & $\mathrm{N}$ & Adjusted $\mathrm{R}^{2}$ & $\mathrm{~F}$ \\
\hline \multirow[t]{2}{*}{$1(\mathrm{OLS})$} & & -6.37 & 0.46 & 0.65 & 240 & 0.80 & 502 \\
\hline & & $(-10.90)$ & $(11.09)$ & $(11.39)$ & & & \\
\hline \multirow[t]{4}{*}{2 (TSLS) } & Niño & -7.43 & 0.39 & 0.76 & 240 & 0.80 & 513 \\
\hline & & $(-12.30)$ & $(9.42)$ & $(12.83)$ & & & \\
\hline & Niño(-12) & -7.58 & 0.39 & 0.77 & 240 & 0.81 & 505.7 \\
\hline & & $(-12.41)$ & $(9.08)$ & $(12.90)$ & & & \\
\hline \multirow[t]{4}{*}{3 (TSLS) } & Niña & -7.43 & 0.39 & 0.76 & 240 & 0.80 & 513 \\
\hline & & $(-12.30)$ & $(9.41)$ & $(12.84)$ & & & \\
\hline & Niña(-12) & -7.59 & 0.39 & 0.77 & 240 & 0.81 & 505.8 \\
\hline & & $(-12.43)$ & $(9.06)$ & $(12.92)$ & & & \\
\hline \multirow[t]{2}{*}{4 (TSLS) } & Temperature & -7.83 & 0.25 & 0.86 & 240 & 0.66 & 237.72 \\
\hline & & $(-11.12)$ & $(5.10)$ & $(13.51)$ & & & \\
\hline \multirow[t]{2}{*}{5 (TSLS) } & Amazon & -7.57 & 0.33 & 0.80 & 240 & 0.76 & 392 \\
\hline & & $(-11.72)$ & $(7.26)$ & $(12.76)$ & & & \\
\hline \multirow[t]{2}{*}{6 (TSLS) } & Aprouague & -7.81 & 0.39 & 0.79 & 240 & 0.84 & 468 \\
\hline & & $(-11.53)$ & $(8.40)$ & $(11.80)$ & & & \\
\hline \multirow[t]{2}{*}{7 (TSLS) } & Comte & -7.37 & 0.40 & 0.75 & 240 & 0.80 & 507 \\
\hline & & $(-12.12)$ & (9.58) & (12.67) & & & \\
\hline \multirow[t]{2}{*}{8 (TSLS) } & Maroni & -7.13 & 0.24 & 0.81 & 240 & 0.67 & 238 \\
\hline & & $(-10.42)$ & $(5.07)$ & (12.88) & & & \\
\hline \multirow[t]{2}{*}{9 (TSLS) } & Oyapock & -7.47 & 0.32 & 0.80 & 240 & 0.76 & 324 \\
\hline & & $(-9.55)$ & $(5.77)$ & (10.11) & & & \\
\hline
\end{tabular}

Instrumental variables: Juveniles, Adults, Niño, Niña, Temperature; Amazon, Aprouague, Comte, Maroni, Oyapock.

However, a Hausman test (Hausman, 1978) rejects the exogeneity of the Stock variable in the harvest function (1). The endogeneity of the fish stock is well known in the litterature of fisheries. According to e.g. Peña-Torres et al. (2007) the endogeneity of the fish stock occurs for two reasons. Firstly, because catch affects biomass negatively. The second reason is linked to the assessment of the fish stock: Virtual Population Analysis (VPA). The VPA was introduced in fish stock assessment by Gulland, (1965). Indeed, the stock variable is calculated using this method which consists in reconstructing historical fish numbers at age using information on death of individuals each year. This death is usually partitioned into catch by fisheries and natural mortality. Then by construction the biomass estimates depend on the catch. A feasible solution for endogeneity problems is the use of lagged variables. 
Nonetheless, this strategy does not solve in a totally convincing way the issue of biomass endogeneity, as contemporaneous catch data is used to estimate current as well as past biomass values, when VPA stock assessment methodology is involved, as this is the case here. As Peña-Torres et al., we use an instrumental variables regression which consists in two stage least squares (TSLS) estimation. The first stage of the estimation consists in making the variable Stock independant by regressing it on all the exogenous variables of the model (here, only Effort), and other instrumental variables. The order condition for identification, which says that there must be at least as many instruments as there are coefficients in equation, is here satisfied. The second stage corresponds to the estimaton of Equation (2), while replacing the Stock variable by its fitted values found in the first stage regression. The results of the TSLS estimation are presented in Table 2. This method is of interest since it enables to evaluate the impact of the pure environmental variables on the stock during the first stage regression. We highlight the corresponding results in Table 3. In Table 3, the estimated effort and stock output elasticities for all models indicate values that are statistically significant at 5 \% level. Comparison between Model 1 and Model 2-9 shows that the effort output elasticity is always higher in the OLS regression (46\%) than in all the TSLS ones (about 35\%, correspondind to the mean value of effort output elasticities), whereas the contrary is observed as the stock output elasticity is concerned. This suggests that the endogeneity problem related to the stock variable artificially increases the value of the effort parameter and diminishes the stock parameter one.

All variables except the dummies for Niño and Niña refer to data transformed by natural logarithms. Coefficient estimates, $t$-values, the Adjusted $R^{2}$, and the Fisher statistics $(F)$ are indicated for all models. The number of observations is added to Table 2 .

The overall explanatory power of all estimated models is high, with $A d$ justed $R^{2}$ s ranging from 0.67 to 0.84 . Moreover, the individual significance level of most coefficients appears to be quite high, denoting a good specification of each model.

The effort output elasticity is significantly different from zero but much lower than one, which clearly indicates decreasing returns to effort within the shrimp's fishery.

The stock output elasticity is also signicantly different from zero. This should have constituted a brake on the observed shrimp's stock depletion since such a positive value implies that harvesting costs depend on stock size. In this case, a fall in the stock size yields an increase in harvesting costs which leads to a decrease in the fishing effort level, and therefore constitutes a mechanical brake on stock depletion (see e.g. Bjørndal et al., 
1993). This brake phenomenon seems to have been at stake in the case of the French Guiana shrimp fishery where the fishermen have substantially decreased their effort level. Nevertheless, this has not prevented the stock from decreasing for a number of years. Our results therefore suggest that the observed shrimp stock collapse is not due to pure economical reasons, but rather to environmental ones in this model.

Table 3: First stage OLS regression. Estimation of the stock with respect to the environmental variables

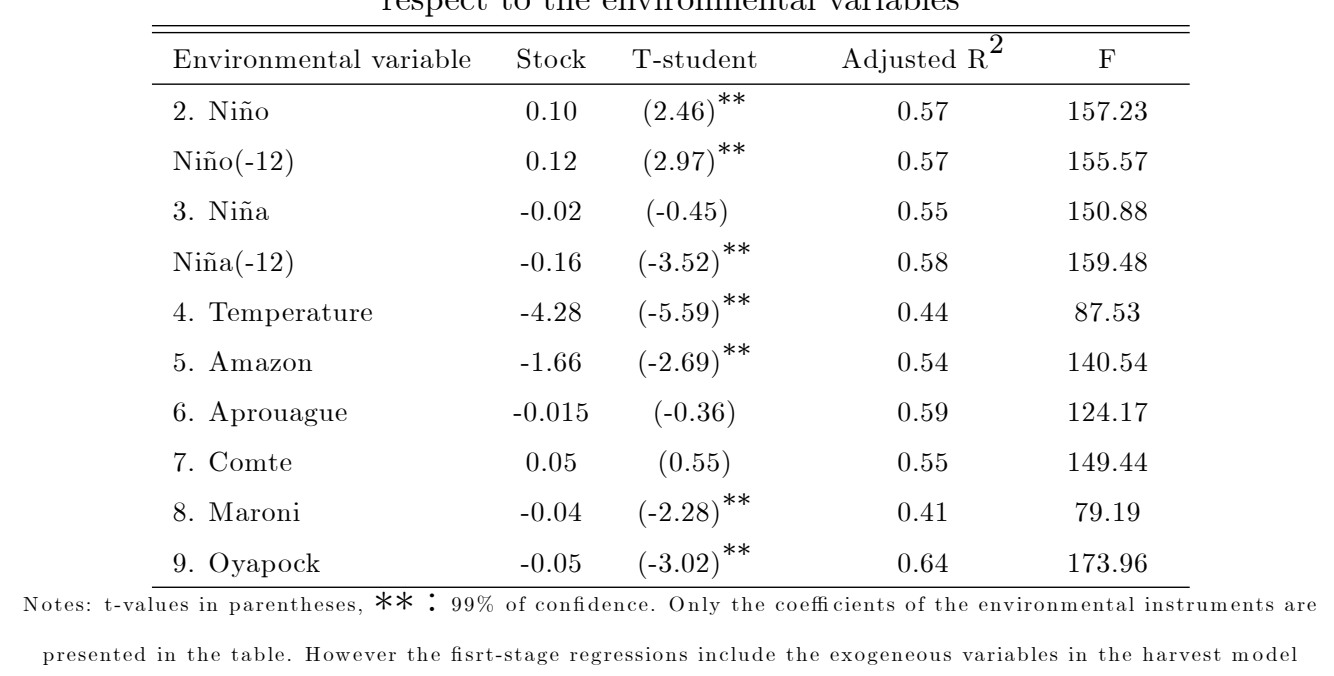

All in all, the stock output elasticity is higher than the effort one. This result is of particular interest since it clearly shows that, in the shrimp fishery of French Guiana, stock contributes to changes in harvest much more than effort.

Only the coefficient of the environmental instruments are presented in the Table 3. However the fisrt-stage regressions include the exogeneous variables in the harvest model. Table 3 indicates that coefficient of dummy variable (Niño) is significantly different from zero (2.46). Moreover the lagged dummies of one year (12 months) Niño(-12) and Niña(-12) are also significant and show that instensity of its impact is higher several months later. Not surprisingly, as the Niño and Niña are opposite phenomena, the stock level is thus positively related to the Niño phenomenon and negatively to the Niña's one.

Niño and Niña climatic phenomena occur on a large scale and modify many environmental factors such as wind, air temperature, water temperature, rainfall, river flows and salinity, and probably also in the nursery area. In particular, as already said, the Niño corresponds to an increase in temperature. However, Table 3 shows that its effect on stock is positive whereas the 
temperature's one is negative. Our results suggest therefore that the Niño's influence on stock seems to go through another channel than temperature. The Niño might indeed affect other important biological processes like sexual maturation, spawning, larvae migration, juvenile feeding and survival, that are not captured by the present analysis. Concerning the Niña, it can correspond to unfavourable local and/or regional hydro-climatic conditions inducing negative effects on the shrimp recruitment (Chaboud et al., 2009). At last, the Niño and the Niña may have some impact on the water temperature, which may in turn influence the patterns of sea currents (Eide et al., 2002).

Table 3 shows that the models that use the Niño and the Niña variables lagged twelve months generate even better results (higher Adjusted $R^{2} \mathrm{~s}$ and $t$-student statistics in both cases). The corresponding elasticities also appear to be higher, suggesting that both phenomena produce their effects on the shrimp's stock and harvest several months after their occurence. Moreover, the Adjusted $\mathrm{R}^{2}$ of the model that integrates the Niña's effects is even higher.

The results concerning the temperature seem particularly interesting since the corresponding coefficient appears to be the highest among all the environmental variables considered in this analysis. Furthermore, the model that uses temperature as an instrument also yields an high Adjusted $\mathrm{R}^{2}(44 \%$ in table 3). Indeed, as mentioned by Garza-Gil et al. (2011), oscillations in temperature seem to have some repercussions on the fish's stock of the continental shelf species, to a greater or a lower degree. The negative temperature stock elasticity suggests that the current sea surface temperatures in French Guiana are probably above the optimal value that yields the highest recruitment.

Table 3 shows that impact of rivers'flow on the stock level, when it is significantly different from zero (Amazon and Maroni and Oyapock), is negative. It is well known that some groups of shrimps are more dependent on freshwater (estuarine extreme species) than others (oceanic-extreme species; Kutkuhn, 1966). Shrimps reproduce offshore so that larval drift can be observed towards the coastline where the nurseries are located. Juveniles will grow there during several weeks. We can hypothesize that juveniles survival depends on the quantity and the quality of the food brought by rivers. However, rivers bring a huge quantity of non-organic matter that could alter the feeding capacity of juveniles. Hence, there probably exists an optimal value for the rivers' flow. On the one hand, a high flow increases the number of survivals because of abundance of food and, on the other hand, a high flow reduces the survival because of too much particules in the water. The Amazon is the river that brings the highest quantity of suspended matter at the world's scale (on average around 4 tons of mud particules per second 
reach the French Guiana; Gratiot et al., 2008; Martinez et al., 2009), which may partly explain the negative relationship between the stock and its flow. One can observe that the Maroni's effects are much weaker than those of the Amazon. Firstly, the flow of the Amazon is several orders of magnitude greater than the Maroni's one. Secondly, the North Brazil Current brings the Amazonian waters from the South East to the North West along the French Guiana coast and therefore pushes the Maroni's waters out of Guiana which weakens the influence of the latter on the stock. Beyond the flow of the rivers considered here, the change of vegetation of watersheds (inland) and nutrient flow to the Guiana-Brazil shrimp grounds may be another important factor affecting shrimp biomass. In order to study the above factors, the surface of the guianan mangrove should be directly integrated to the Cobb-Douglas production function next to the effort variable, as in Barbier (1998, 2000, 2003).

\section{Conclusion}

This paper shows that a Cobb-Douglas harvest production function is appropriate to describe the French Guiana shrimp fishery. The model relating the quantity of shrimp harvested to the number of days at sea and to the shrimp population seems to be well supported by the set of data used if augmented by some relevantly chosen environmental variables. The temperature of the sea surface in the fishing ground, the influence of the Niño and the Niña and the river's flow seem indeed to contribute to the explanation of changes in the shrimp's harvest. Among all, the sea temperature in the fishing ground appears to be the most influential. The increase of SST by global warming is significant in French Guiana area (about $0.65^{\circ} \mathrm{C}$ in 20 years). Nevertheless, there seems not to exist any order of importance between the other factors studied in this paper. However the impact of the Amazon is greater than the others rivers'one.

Our results concerning SOI effects also suggest that climatic change may influence stocks and harvest levels by the indirect effects in winds, waves, rains, suspended matter, sediments. More broadly, it may alter the configuration of ocean currents and, consequently, the most favourable regions for fishing (Arnason, 2003). This phenomenon can be small or large. The rivers' flow also tends to vary when climate changes. In particular, it rises during the rainy season (Callède et al., 2004) and climatic predictions states that the length of this season will increase in the future. Our study highlights therefore some important effects the climatic change may have on the shrimp's stock through its influence on the flow of the big amazonian rivers. 
The potential increase in the long term trends in SST and the Amazon river flow may lead to a collapse of the stock.

In the French Guiana shrimp fishery, the regulation has been implemented through a system of licenses. Policymakers try to regulate the fishery through the control of the fishing effort level. However, the latter explains a much smaller proportion of the harvest variations than the stock (only $35 \%$, see Table 2 where the mean value of effort output elasticities is about 35\%). Moreover, our results suggest that the stock is very dependent on environmental factors. This explains why the impact of the above policy is quite weak. One may therefore question the relevance or the effectiveness of such licenses that are even not always profitable.

Our paper ignores some other important features of shrimp fisheries that also depend very much on local conditions: mixing of water masses, water salinity, currents, nutrients, turbidity. The physical environment has been recognized as being the main factor driving the biological productivity and essentially influencing all processes in the sea. Other factors responsible for a great part of the observed variability in marine data are biological interactions and the anthropogenic impact (Daskalov, 1999). Which exact role do the above factors play is however very hard to precise. Further avenues of research may consist in explicitly integrating the above factors into the analysis. However, since the harvest production function used in this paper is found to be appropriate, a second step of the present work would consist in including explicitly other important instruments into the analysis like pure biological or ecological factors (e.g. nutrient flow from rivers). The guianan mangrove may also play a particularily important role and should thus be integrated to such an analysis. 


\section{References}

Aragon-Noriega, E.A., Alcántara-Razo, E. (2005), "Influence of sea surface temperature on reproductive period and size at maturity of brown shrimp (Farfantepenaeus californiensis) in the Gulf of California", $M a-$ rine Biology 146, 373-379.

Arnason, R. (2003), "Global warming and North Atlantic fisheries: attempting to assess the economic impact", Working paper presented at the FAME workshop, Copenhagen. ICES Oceanography Committee ICES CM 2006/OCC: 12 REF. ACFM, ACE, RMC.

Baisre, J. A., Arboleya, Z. (2006), "Going against the flow: Effects of river damming in Cuban fisheries", Fisheries Research 81(23), 283-292.

Barbier, E. B. (1998), "Valuing mangrove-fishery linkages-A case study of Campeche, Mexico", Environmental and Resource Economics 12(2), 151-166.

Barbier, E. B. (2000), "Valuing the environment as input: review of applications to mangrove-fishery linkages" Ecological Economics, 35(1), 47-61.

Barbier, E. B. (2003), "Habitat-fishery linkages and mangrove loss in Thailand", Contemporary Economic Policy, 21(1), 59-77.

Beaumont, L.J., Hughes, L. (2002), "Potential changes in the distributions of latitudinally restricted Australian butterfly species in response to climate change". Global Change Biology 8, 954-971.

Bjørndal, T. (1987), "Production Economics and Optimal Stock size in a North Atlantic Fishery", Scandinavian Journal of Economics 89, 14564 .

Bjørndal, T. (1989), "Production in a Schooling Fishery: The case of the North Sea Herring Fishery", Land Economics 65(1), 49-56.

Bjørndal, T., Conrad, D.V., Salvanes, K.G. (1993), "Stock Size, Harvesting Costs, and the Potential for Extinction: the Case of Sealing", Land Economics 69(2), 156-167.

Bjørndal, T., Gordon, D.V. (1993), "The Opportunity Cost of Capital and Optimal Vessel Size in the Norwegian Fishing Fleet", Land Economics 69(1), 98-107. 
Brown, J.H., Stevens, G.C., Kaufman, D.M. (1996), "The geographic range: size, shape, boundaries, and internal structure". Ann. Rev. Ecol. Syst. 27, 597-623.

Callède, J., Guyot, J.L., Ronchail, J., L'Hote, Y., Niel, H., De Olivera, E. (2004), "Evolution of the River Amazon's discharge at Óbidos from 1903 to 1999", Hydrological Sciences Journal, 49(1), 85-97.

Clark, C. W. (1976), "Mathematical Bioeconomics: The Optimal Management of Renewable Resources", New York: John Wiley and Sons.

Chaboud, C., Thébaud, O. (2009), "18th World IMACS / MODSIM Congress", Cairns, Australia 13-17 July 2009.

Daskalov, G. (1999), "Relating fish recruitment to stock biomass and physical environment in the Black Sea using generalized additive models", Fisheries Research 41, 1-23.

Dunlap, R. E. (1991), "Trends in public opinion toward environmental issues: 1965 à 1990", Society Es Natural Resources 4(3), 285-312.

Eide, A., Heen, K. (2002), "Economic impacts of global warming: A study of the fishing industry in North Norway", Fisheries Research 56(3), 261-274.

Garza-Gil, M. D., Torralba-Cano, J., Varela-Lafuente, M.M. (2011), "Evaluating the economic effects of climate change on the European sardine fishery", Regional Environmental Change 11, 87-95.

Gaston, K. (1990), "Patterns in the geographical ranges of species". Biol. Rev. 65, 105-129.

Gratiot, N., Anthony, E.J., Gardel, A., Gaucherel, C., Proisy, C., Wells, J.T. (2008), "Significant contribution of the 18.6 year tidal cycle to regional coastal changes", Nature Geoscience 1, 169-172.

Gulland, J.A. (1965), "Estimation of mortality rates", Appendix to Arctic Fisheries Working Group Report, ICES C.M. Doc N 3.

Hart, P.J.B., Reynolds, J.D. (2002), "Banishing ignorance: underpinning fisheries with basic biology", Handbook of fish biology and fisheries (Ed. by P. J. B. Hart and D. Reynolds), pp 1-12. Blackwell Science Ltd, Oxford. 
Hausman, J.A. (1978), "Specification Tests in Econometrics", Econometrica $46(6), 1251-1271$.

Healey, M.C., Hennessey, T. (1998), "The paradox of fairness: The impact of escalating complexity on fishery management", Marine Policy 22 (2) , pp. 109-118.

Hengeveld, R., Haeck, J., (1982), "The distribution of abundance. I Measurements". J. Biogeogr. 9, 303-316.

Huntley, B. (1994). "Plant species' response to climate change: implications for the conservation of European birds". Ibis 137, 127-138.

Ishimura, G., Herrick, S., Sumaila, U.R. (2013), "Fishing games under climate variability: transboundary management of Pacific sardine in the California Current System", Environmental Economics and Policy Studies 15(2), 189-209.

Kutkuhn, J.B. (1966), "Dynamics of a penaeid shrimp population and management implications", Fishing Bulletin 65, 313-338.

Lampert, L. (2011a), "Etude de la crise de la pêche de la crevette en Guyane. Volume 1 : Effets de la pêcherie-hypothèses des causes", Rapport RST IFREMER/BIODIVHAL 2011-5, Cayenne, 52 p. + annexe ; http://archimer.ifremer.fr/doc/00075/18584/16137.pdf

Lampert, L. (2011b), "Mode d'emploi du script « R » pour le calcul par VPA du nombre de recrus de crevettes et de leur biomasse", Rapport RST IFREMER/BIODIVHAL 2011-1, Cayenne, 40 p. + annexe ; http://archimer.ifremer.fr/doc/00075/18615/16168.pdf

Lawton, J.H. (2000), "Community ecology in a changing world". Kinne O (Ed), Excellence in Ecology, 11, Ecology Institute, Oldendorf/Luhe, Germany.

Mack, R.N. (1996). "Predicting the identity and fate of plant invaders: emergent and emerging approaches". Biol. Cons. 78, 107-121.

Martinez, J.M., Guyot, J.L., Filizola, N., Sondag, F. (2009), "Increase in suspended sediment discharge of the Amazon River assessed by monitoring network and satellite data", Catena 79, 257-264.

Maurer, B.A. (1999), "Untangling ecological complexity". University of Chicago Press, Chicago. 
Mooney, H.A. (1991), "Biological response to climate change: an agenda for research". Ecol. Appl. 1, 112-117.

Peña-Torres, J., Agostini, C., Vergara, S. (2007), "Fish Stock Endogeneity in a Harvest Function: 'El Niño' Effects on the Chilean Jack Mackerel Fishery", Revista de Anàlisis Económico 22(2), 75-99.

Reynolds, R. W., Rayner, N. A., Smith, T. M., Stokes, D. C., \& Wang, W. (2002), "An Improved In Situ and Satellite SST Analysis for Climate", Journal of Climate 15(13), 1609-1625.

Rogers, D.J., Randolph, S.E. (1993), "Distribution of tsetse and ticks in Africa: past, present and future". Parasit. Today 9, 266-271.

Schaefer, M. B. (1957), "Some considerations of population dynamics and economics in relation to the management of marine fishes", Journal of the Fisheries Research Board of Canada 14, 669-81.

Sparre, P., Venema, S.C. (1998), "Introduction to tropical fish stock assessment. Part 1 Manual", Rev. 2. FAO. Fish. Tech. Pap. 306/1 (Rev. 2), Rome, FAO, 407 p.

Sun, C.-H., Chiang F.-S., Tsoa E., Chen M.-H. (2006), "The effects of El Niño on the mackerel purse-seine fishery harvests in Taiwan: An analysis integrating the barometric readings and sea surface temperature", Ecological Economics 56(2), 268-279.

Vendeville, Ph., Rosé J., Viera A., and Blanchard F. (2008), "Durabilité des activités halieutiques et maintien de la biodiversité marine en Guyane", Rapport IFOP-CPER. Cayenne : Ifremer, 316 p. + annexe ; http://archimer.ifremer.fr/doc/00085/19595/

Yagi, M., Managi, S. (2011), "Catch limits, capacity utilization and cost reduction in Japanese fishery management", Agriculture Economics 42, 577-592. 